\title{
Syndactyly, ectodermal dysplasia, and cleft lip/palate
}

\author{
Joël Zlotogora
}

A few years ago Zlotogora $e t a l^{1}$ and Oğur and Yüksel $^{2}$ independently reported two unrelated families with a syndrome including cleft lip and palate, syndactyly, ectodermal dysplasia, and psychomotor retardation. After comparison of the clinical manifestations it became clear that they represent the same syndrome ${ }^{3}$ (MIM *22500). Since then another family with three affected children has been published. ${ }^{4}$ In 1991 , Bustos et $a \hat{l}$ reported seven related families containing 20 affected persons with similar clinical features but normal psychomotor development, and the condition was presented as a new syndrome (MIM 225060). I propose that these two conditions represent the same pleiotropic syndrome of syndactyly, ectodermal dysplasia, and cleft lip/palate. After widening the spectrum of the syndrome, patients from two additional reports, who were also thought to represent different new syndromes, may be included as affected with this syndrome.$^{67}$ In particular, in 1976 Wiedemann et al reported a family with three affected children who at the time of the first report ${ }^{1}$ were thought to be affected with a different syndrome because of the absence of cleft lip/palate and the normal intelligence. Another affected patient was cited by Gorlin et al, ${ }^{8}$ but insufficient details were available and therefore this patient is not included in this summary.

The summary of the clinical manifestations is based on 31 patients affected with the syndrome observed from the age of 4 months to 65 years (table 1 ).

\section{Clinical features}

The appearance of the affected patients is typ- ical, with sparse, abnormal hair, protruding ears, and often cleft lip/palate. Cutaneous syndactyly of the fingers and toes is often present. Mental status may be impaired.

\section{FACIAL APPEARANCE (FIG 1)}

The appearance of the affected persons is very similar because of the shape of their face and the abnormal and sparse hair. Cleft lip/palate is present in most patients, and in those without cleft lip/palate the philtrum or uvula or both are often abnormal. ${ }^{5}$ The ears are anteverted and often abnormal.

\section{CUTANEOUS SYNDACTYLY}

Cutaneous syndactyly is frequently present in fingers 2-3-4 in different combinations and with different degrees of severity. One patient had only webs between fingers $2-3-4^{6}$ and some patients did not have syndactyly. ${ }^{5}$ In the feet syndactyly of toes $2-3$ is usually present. In two of the children there was in addition syndactyly of toes $4-5$. $^{7}$

\section{ECTODERMAL DYSPLASIA}

The hair is sparse and short with structural changes which have been described as pili torti ${ }^{15}$ or kinky hair. ${ }^{246}$ Older patients have been reported to have complete alopecia by the fifth decade. ${ }^{5}$ The eyebrows are sparse, in particular laterally. The skin is dry and thick on the palms and soles. Palmar and plantar hyperkeratosis is progressive. In one patient followed since early infancy the hyperkeratosis only appeared at the age of 4 years and has

Clinical features of patients with the syndrome of syndactyly, ectodermal dysplasia, and cleft lip/palate

\begin{tabular}{|c|c|c|c|c|c|c|c|}
\hline & \multicolumn{6}{|c|}{ Reference } & \multirow[b]{2}{*}{ Total } \\
\hline & 1 & 2 & 4 & 5 & 6 & 7 & \\
\hline Number of patients examined & 2 & 2 & 3 & 20 & 1 & 3 & 31 \\
\hline Total & 2 & 2 & 5 & 27 & $1+3 ? *$ & 3 & 40 (43?*) \\
\hline Sex & $1 \mathrm{M} / 1 \mathrm{~F}$ & $2 \mathrm{M}$ & $5 \mathrm{M}$ & $12 / 15 \mathrm{~F}$ & $1 \mathrm{~F}$ & $2 \mathrm{M} / 1 \mathrm{~F}$ & $22 \mathrm{M} / 18 \mathrm{~F}$ \\
\hline Cleft lip/palate & + & + & + & $40 \%$ & + & - & ++ \\
\hline Abnormal ears & $\begin{array}{l}\top \\
+\end{array}$ & + & + & $70 \%$ & - & + & ++ \\
\hline Hair sparse, short & + & + & + & $100 \%$ & + & + & ++ \\
\hline Scanty eyebrows & + & + & + & $100 \%$ & + & + & $++t$ \\
\hline Plantar/solar hyperkeratosis & + & $\begin{array}{l}+ \\
+\end{array}$ & + & $100 \%$ & $?$ & + & +++ \\
\hline Hypohidrosis & - & + & + & - & + & + & $+1+$ \\
\hline Abnormal teeth & + & + & + & $70 \%$ & + & + & ++ \\
\hline Abnormal nails & - & - & + & $60 \%$ & I & + & $\begin{array}{l}T^{\top} \\
+1-\end{array}$ \\
\hline Syndactyly & + & + & + & $65 \%$ & $+1-$ & + & ++ \\
\hline Mental retardation & + & + & + & - & - & - & $\begin{array}{l}+1- \\
+1-2\end{array}$ \\
\hline
\end{tabular}

Department of Human Genetics, Hadassah Medical Centre, Hebrew University, POB 12,000 Jerusalem, i191120 Israel

J Zlotogora

* The three sibs of the proband died neonatally; they had cleft lip/palate and may have been affected. 


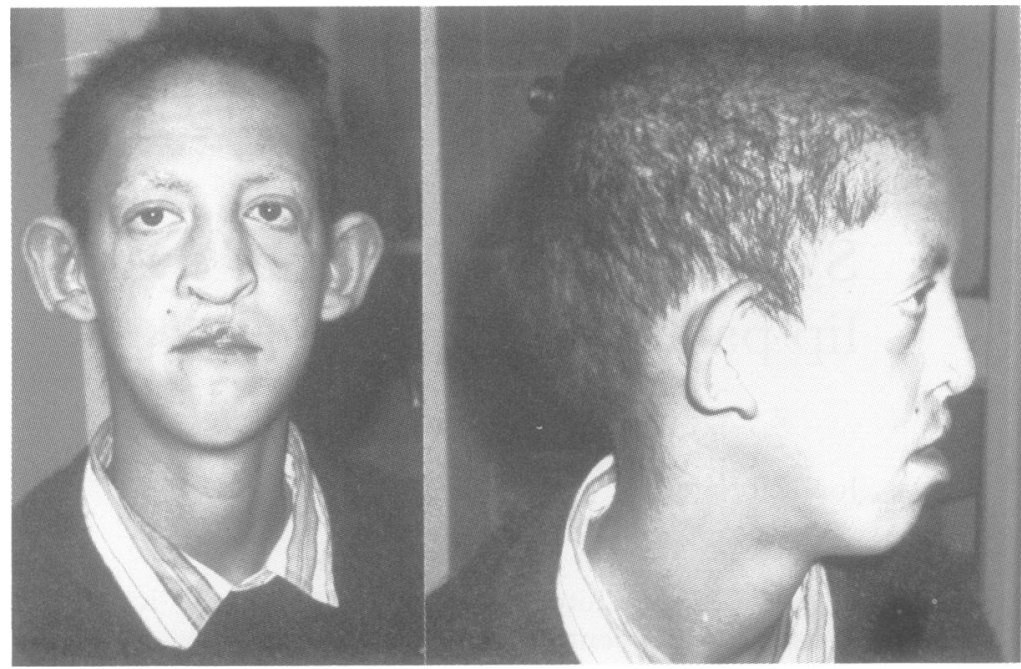

Figure 1 The proband in Zlotogora et al ${ }^{1}$ at the age of 11 years. Note sparse and kinky hair, oval face, and anteverted and abnormal ears. The cleft lip has been repaired.

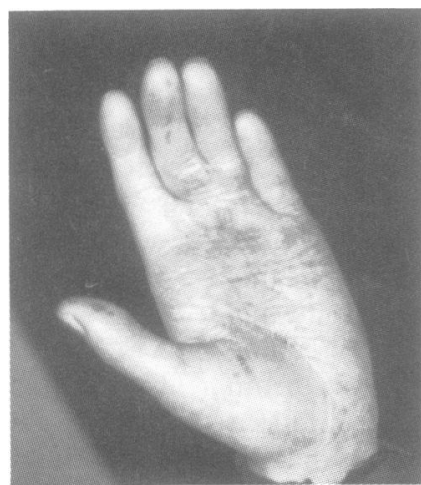

Figure 2 Left hand of the proband. Note syndactyly of fingers 3 and 4, hyperkeratosis, and hypoplastic creases.

been getting worse since then (fig 2). ${ }^{3}$ The dermatoglyphics are often hypoplastic and in some patients simian or Sydney palmar lines have been described. ${ }^{17}$ Anomalies of the teeth are found, such as delayed eruption, microdontia, hypodontia, and anodontia in adults. The nails are normal in many patients but onychodysplasia may be present.

All the patients have normal tolerance to heat, but most of them have hypohidrosis.

\section{ADDITIONAL CLINICAL FEATURES}

Additional features present in only a few patients include deafness, ${ }^{24}$ genitourinary abnormalities, ${ }^{124}$ nipple anomalies, ${ }^{124}$ and lumbar lordosis. ${ }^{67}$ One patient had hypoplastic lacrimal puncta, camptodactyly of the fourth toes, and hypoplastic fifth toes. ${ }^{6}$

\section{Psychomotor development}

While mental retardation was thought to be an obligatory feature when the syndrome was first delineated, it appears that mental development may differ from family to family. In three families ${ }^{124}$ all the affected children were mentally retarded. Normal intelligence was reported in two families ${ }^{67}$ and also in all the patients from the seven families described by Bustos et $a l^{5}{ }^{5}$ who most probably had a common ancestor.
These interfamilial differences may be the result of different allelic mutations. Another possibility may be that mental retardation is the result of a closely linked gene.

\section{Variability}

The variability of the syndrome is evident from the summary of clinical features in the table. In general, variability was less evident among affected sibs. In the large group of patients reported by Bustos et al, ${ }^{5}$ four affected persons had neither syndactyly nor cleft lip/palate. If those patients had been sporadic cases, they may have been diagnosed as affected with ectodermal dysplasia. These patients show that it may be that the syndrome represents a severe form of a more common ectodermal dysplasia syndrome.

\section{Prognosis}

Affected adults have been reported ${ }^{56}$ and they did not present any particular health problems, but there are still no data on their ability to reproduce. Most adults reported were unmarried and the only affected woman who has been pregnant had two abortions. ${ }^{5}$

Some of the affected children died neonatally or at a young age. In one family an affected girl died suddenly at home at the age of 8 months, ${ }^{1}$ and in another family one affected brother died at the age of 10 days and an affected half brother died neonatally. ${ }^{4}$ In the family of the patient reported by Richieri-Costa et at three children with cleft lip and palate, perhaps affected with the syndrome, died neonatally. In addition, stillbirth and neonatal or early childhood death of children who appeared to be unaffected were reported in three families. ${ }^{124}$ The reason for these deaths is unknown.

\section{Inheritance}

The syndrome is inherited as an autosomal recessive trait. It has been reported in both males and females. In all the families reported up to now the parents of the affected children 
were related. The seven families reported by Bustos $e t a l^{5}$ originated from an isolated community and most probably had a common founder.

\section{Differential diagnosis}

EEC (ectrodactyly, ectodermal dysplasia, and cleft lip/palate) is a relatively common syndrome which includes most of the manifestations of the syndactyly, ectodermal dysplasia, and cleft lip/palate syndrome. ${ }^{8}$ The major differences are the mode of inheritance, since the EEC syndrome is an autosomal dominant trait, and the limb malformations, which are usually ectrodactyly in the EEC syndrome ( $65 \%$ of patients). However, in an isolated patient the differential diagnosis may be difficult; the presence of palmar and plantar hyperkeratosis in older patients may be particularly useful to distinguish between the two syndromes.

Among the other syndromes with ectodermal dysplasia, cleft lip/palate, and limb malformations, a few include syndactyly and ectodermal dysplasia. Roselli and Guilenett ${ }^{9}$ reported four patients with hypohidrotic ectodermal dysplasia, cleft lip and palate, changes in the nails and teeth, and mental retardation. However, some of these children had, in addition, dystrophic skin on the face with a tendency to desquamation, aplasia or hypoplasia of the thumb, and popliteal and perineal pterygium. Therefore, these children appear to be affected with a distinct syndrome even though they were included by McKusick ${ }^{10}$ in the same entry as syndactyly, ectodermal dysplasia, and cleft lip/ palate syndrome (MIM 22500). Also included are the three patients reported by Bowen and Armstrong ${ }^{11}$ with mental retardation, cleft lip and palate, and syndactyly of the toes with synostosis in one of them. The adhesion of the eyelids and skin defects in two patients indicates that they are affected with a different syndrome.

Martinez et $a l^{12}$ also reported a child with cleft lip and palate, syndactyly of fingers 1 and 2 , and structural defects of the hair. However, the coarse and abundant hair with microcephaly, hypertelorism, and prominent eyes make the appearance of this child very different from the one described in the present syndrome.

1 Zlotogora J, Zilberman Y, Tenenbaum A, Wexler MR. Cleft lip and palate, pili torti, malformed ears, partial syndactyly of fingers and toes and mental retardation. A new synof fingers and toes and mental retardat

2 Oğur G, Yüksel M. Association of syndactyly, ectodermal dysplasia, and cleft lip and palate: report of two sibs from dysplasia, and cleft lip and palate: repo
Turkey. $\mathcal{F}$ Med Genet 1988;25:37-40.

3 Zlotogora J, Ogur G. Syndactyly, ectodermal dysplasia, and cleft lip and palate. $\mathcal{F}$ Med Genet 1988;25:503.

4 Rodini ESO, Richieri-Costa A. Autosomal recessive ectodermal dysplasia, cleft lip/palate, mental retardation and syndactyly: the Zlotogora-Oğur syndrome. Am $f$ Med Genet 1990;36:473-6.

5 Bustos T, Simosa V, Pinto-Cisternas J, et al. Autosomal recessive ectodermal dysplasia. I. An undescribed dysplasia/malformation syndrome. Am F Med Genet 1991;41: 398-404.

6 Richieri-Costa A, Guion-Almeida ML, Freire-Maia N, Pinheiro M. Autosomal recessive cleft lip/palate, ectodermal dysplasia, and minor acral anomalies: report of a Brazilian family. Am 7 Med Genet 1992;44:158-62.

7 Wiedemann HR, Grosse FR, Dibbern H. Das charakteristische Syndrom. Blickdiagnose von Syndromen. Ein Atlas teristische Syndrom. Blickdiagnose von Syndromen. Ein

8 Rodini ESO, Richieri-Costa A. EEC syndrome: report on 20 new patients, clinical and genetic considerations. $\mathrm{Am}$ 20 new patients, clinical and genetic considerations. $\mathrm{Am}$ f Med Genet 1990;37:42-53.

9 Rosselli D, Guilieneti R. Ectodermal dysplasia. Br $\mathcal{f}$ Plast Surg 1961;14:190-204.

10 McKusick VA. Mendelian inheritance in man. Catalogs of autosomal dominant, autosomal recessive, and X-linked phenotypes. Baltimore: Johns Hopkins University Press, 1992.

11 Bowen P, Armstrong HB. Ectodermal dysplasia, mental retardation, cleft lip/palate and other anomalies in three sibs. Clin Genet 1976;9:35-42.

12 Martinez RB, Monasterio LA, Pinherio M, Freire-Maia N. Cleft lip/palate-oligodontia-syndactyly-hair alterations, a new syndrome. Review of the conditions combining ectodermal dysplasia with cleft lip/palate. Am $\mathcal{f}$ Med Genet 1987;27:497-506. 